\title{
Kyphotic Angle Progression of Thoracic and Thoracolumbar Tuberculous Spondylitis after Surgical Treatment: Comparison with Predicted Kyphosis Outcome after Conservative Treatment
}

\author{
Soon-Eok Kwon*, Jae-Hyuk Shin ${ }^{\dagger}, \mathrm{Ki}^{*} \mathrm{Ho} \mathrm{Na}^{\ddagger}$, Yoon-Chung Kim ${ }^{\S}$, Kee-Yong $\mathrm{Ha}^{\S}$ \\ *Department of Orthopaedic Surgery, The Chungju St. Mary's Hospital, Chungju, Korea, \\ ${ }^{\dagger}$ Department of Orthopaedic Surgery, Hangang Sacred Heart Hospital, Hallym University College of Medicine, Seoul, Korea, \\ ${ }^{\ddagger}$ Department of Orthopaedic Surgery, St. Paul's Hospital, The Catholic University of Korea \\ College of Medicine, Seoul, Korea, \\ ${ }^{\S}$ Department of Orthopaedic Surgery, Seoul St. Mary's Hospital, The Catholic University of Korea
} College of Medicine, Seoul, Korea

Study Design: Retrospective comparative study

Purpose: To compare the progression of the kyphotic angle (KA) in a surgically treated group with the predicted outcome of a conservatively treated group.

Overview of Literature: Late onset kyphosis is a complication of tuberculous spondylitis making its prevention a major goal of surgery.

Methods: Twenty six consecutive patients underwent an anterior reconstruction and posterior instrumented fusion in conjunction with antituberculous chemotherapy. The mean follow up was 56 months (range, 28 to 112 months). The patients were divided into subgroups based on the involved region of the thoracic and the thoracolumbar spine, initial KA, and the initial vertebral body loss $(\operatorname{VBL}(\mathrm{x}))$. The predicted $\mathrm{KA}\left(\mathrm{KA}_{P_{d}}\right)$ was calculated using the formula, $\mathrm{KA}_{P d}=5.5+30.5 \mathrm{VBL}(\mathrm{x})$, to predict the final gibbus deformity. Kyphotic angle progression ( $\triangle \mathrm{KA}$ ) based on the radiographic measurements after surgery $\left(\Delta \mathrm{KA}_{\mathrm{R}}\right.$ ), and the predicted outcome of conservative treatment ( $\triangle \mathrm{KA}$ ) with chemotherapy were compared.

Results: Among the subgroups of the regions involved and initial KA, the $\triangle \mathrm{KA}$ was radiographically superior with a reduced amount of kyphogenesis in the surgery group than the predicted outcome of the conservatively treated patients ( $p$ $<0.05)$. The radiographic $\triangle \mathrm{KA}$ was similar $(\mathrm{p}>0.05)$ with $\operatorname{VBL}(\mathrm{x}) \leq 0.5$ in the $\operatorname{VBL}(\mathrm{x})$ subgroup.

Conclusions: These results showed that in the $\operatorname{VBL}(\mathrm{x})$ subgroup, an initial $\operatorname{VBL}(\mathrm{x}) \leq 0.5$ is an indication of conservative antituberculous chemotherapy without surgery.

Key Words: Tuberculous spondylitis, Kyphosis, Initial vertebral body loss

\section{Introduction}

Kyphosis and paralysis are the major outcomes of spinal tuberculosis (TB). Spinal TB can stabilize spontaneously without progression of the deformity. However, the development of a kyphotic deformity is a serious complication. It is not only cosmetically unpleasant but also impairs the cardiopulmonary function, causes pain from nerve impingement between the ribs and pelvis, and/or causes late-onset

Received Dec 29, 2008; 1st revised Sep 15, 2009; 2nd revised Oct 11, 2009; accepted Oct 12, 2009

Corresponding author: Kee-Yong Ha, MD

Department of Orthopaedic Surgery, Seoul St. Mary's Hospital, The Catholic University of Korea College of Medicine

505 Banpo-dong, Seocho-gu, Seoul 137-040, Korea

Tel: +82-2-590-1464, Fax: +82-2-535-9834, E-mail: kyh@ catholic.ac.kr 
paraplegia. A severely deformed kyphosis can be treated only by corrective surgery. However, this is a challenging option with a high complication rate ${ }^{1}$. A kyphotic deformity can be prevented if spinal TB is diagnosed early and antituberculosis chemotherapy is administered promptly. However, some kyphotic deformity may still develop even with adequate medical treatment. The sequela of a kyphotic deformity has been a subject of research into the treatment of patients with spinal TB.

The fifth report of the Medical Research Council Working Party on Tuberculosis of the Spine (MRC) $)^{2}$ stated the following: 1) a kyphotic deformity develops most severely in the thoracic spine region, which is followed in order by the thoracolumbar, lumbar and lumbosacral spine after treatment with standard TB medications; 2) the greater the pretreatment kyphotic deformity, the less likely the kyphosis will progress further after initiating treatment; and 3) further collapse is appreciable when the initial vertebral body loss upon admission was small ( $<2$ vertebrae), while the initial vertebral body loss of two or three segments showed no further collapse on average ${ }^{2}$.

Rajasekaran and Shanmugasundaram ${ }^{3}$ reported that kyphosis progresses gradually in the thoracic and thoracolumbar spine above L2 during conservative treatment with anti-tuberculous chemotherapy. Regarding the degree of kyphogenesis, the initial vertebral body loss $(\operatorname{VBL}(\mathrm{x}))$ was considered to be the determining factor, while the initial kyphotic angle (KA) was not. A predicted $\mathrm{KA}\left(\mathrm{KA}_{\mathrm{Pd}}\right)$ was formulated as ' $\mathrm{KA}_{\mathrm{Pd}}=5.5+30.5 \mathrm{VBL}(\mathrm{x})$ ' with a correlation coefficient of 0.83 and an accuracy of $90 \%$. This formula applies to the thoracic and thoracolumbar region above L2, which forms a normal kyphotic curve. In the lumbar spine, the lordotic curvature contributes to the progression of the deformity in the thoracic spine ${ }^{4}$.

This study examined the change in the sagittal profile after surgical treatment in tuberculous (Tbc) spondylitis patients, and compared it with the predicted change of the sagittal profile after chemotherapy alone. It is believed that the indications for surgery or conservative treatment might be better determined using this information.

\section{Materials and Methods}

\section{Patients}

This study was approved by the institutional review board. Twenty six patients ( $\mathrm{M}: \mathrm{F}=12: 14)$ were examined after undergoing surgery for thoracic and thoracolumbar TB between 1992 and 2001. The mean follow up period and age was 56 months (range, 28 to 112 months) and 41.7 years (range, 18 to 73 years), respectively. The regional subgroups included 12 and 14 cases in the thoracic (T: from $\mathrm{T} 2$ to $\mathrm{T} 10$ ) and thoracolumbar (TL: from $\mathrm{T} 11$ to $\mathrm{L} 2$ ), respectively.

\section{Operation method}

Anterior radical surgery with an autogenous iliac bone graft was performed in all cases, and posterior instrumentation (TSRH $^{\mathrm{TM}}$; Texas Scotish Rite Hospital, MedtronicSofamor Danek, Memphis, TN, USA) and fusion were performed using an autogenous cancellous bone graft.

\section{Measurement}

The KA progressions ( $\Delta \mathrm{KA}$ )'s were obtained. $\Delta \mathrm{KA}$ following surgery $\left(\Delta \mathrm{KA}_{\mathrm{R}}\right)$ was measured by comparison of the difference in the kyphotic angle of the last follow up standing lateral radiograph $\left(\mathrm{KA}_{\text {Final }}\right)$ to the preoperative standing lateral radiograph $\left(\mathrm{KA}_{\mathrm{Pre}}\right)$ (Table 1). The radiographic measurements were performed by two independent spine surgeons that did not participate in the surgery. Each surgeon performed the measurements twice; the mean of the measurements was used as the final value. The $\mathrm{KA}_{\mathrm{Pd}}$, or the final gibbus deformity, was calculated using the formula ' $\mathrm{KA}_{\mathrm{Pd}}=5.5+30.5 \operatorname{VBL}(\mathrm{x})$ ' by measuring the $\operatorname{VBL}(\mathrm{x})$. The estimated $\mathrm{KA}_{\mathrm{Pd}}$ was calculated presuming that only antituberculous chemotherapy was administered as conservative treatment. Predicted kyphotic angle progression $(\Delta$ $\mathrm{KA}_{\mathrm{P}}$ ) was calculated by difference of $\mathrm{KA}_{\mathrm{Pd}}$ and $\mathrm{KA}_{\text {Pre }}$ (Table 1).

\section{(1) Measurement of the kyphotic angle}

The measured KA angle was the Cobb's angle between the upper border of the upper normal vertebra and the lower border of the lower normal vertebra on a simple standing lateral radiograph of the lesion, as previously reported by the $\mathrm{MRC}^{2,5,6}$.

\section{(2) Measurement of the preoperative $\operatorname{VBL}(x)$}

Rajasekaran and Shanmugasundaram ${ }^{3}$ assessed the loss of the vertebral body, which we regarded as $\mathrm{VBL}_{1}$, using the following method: divide the lateral height of each vertebra 
Table 1. Patient demographics

\begin{tabular}{|c|c|c|c|c|c|c|c|c|c|c|c|c|}
\hline Patients & Age & Gender & $\begin{array}{c}\text { FU } \\
\text { (month) }\end{array}$ & Level & $\begin{array}{l}\text { Involved } \\
\text { vertebra }\end{array}$ & $\begin{array}{c}\mathrm{KA}_{\text {Pre }} \\
\left(^{\circ}\right)\end{array}$ & $\begin{array}{l}\mathrm{KA}_{\text {Post }} \\
\left(^{\circ}\right)\end{array}$ & $\begin{array}{l}\mathrm{KA}_{\text {Final }} \\
\left(^{\circ}\right)\end{array}$ & $\begin{array}{c}\mathrm{KA}_{\mathrm{Pd}} \\
\left(^{\circ}\right)\end{array}$ & $\operatorname{VBL}(\mathrm{x})$ & $\begin{array}{c}\Delta \mathrm{KA}_{\mathrm{R}} \\
\left(\mathrm{KA}_{\text {Final }}-\mathrm{KA}_{\mathrm{Pre}}\right)\end{array}$ & $\begin{array}{c}\Delta \mathrm{KA}_{\mathrm{P}} \\
\left(\mathrm{KA}_{\mathrm{Pd}}-\mathrm{KA}_{\mathrm{Pre}}\right)\end{array}$ \\
\hline 1 & 65 & M & 39 & $\mathrm{~T}$ & 7,8 & 20 & 15 & 22 & 23.5 & 0.59 & 2 & 3.5 \\
\hline 2 & 43 & M & 29 & $\mathrm{~T}$ & 5,6 & 15 & 11 & 15 & 19.2 & 0.45 & 0 & 4.2 \\
\hline 3 & 54 & M & 45 & $\mathrm{~T}$ & $3,4,5$ & 38 & 20 & 25 & 37.2 & 1.04 & -13 & -0.8 \\
\hline 4 & 29 & $\mathrm{~F}$ & 47 & $\mathrm{~T}$ & 6.7 & 25 & 16 & 35 & 26.5 & 0.69 & 10 & 1.5 \\
\hline 5 & 17 & M & 27 & $\mathrm{~T}$ & 2,3 & 35 & 30 & 35 & 37.5 & 1.05 & 0 & 2.5 \\
\hline 6 & 26 & $\mathrm{~F}$ & 49 & $\mathrm{~T}$ & $5,6,7$ & 30 & 20 & 25 & 26.9 & 0.7 & -5 & -3.2 \\
\hline 7 & 36 & $\mathrm{~F}$ & 56 & $\mathrm{~T}$ & 7,8 & 7 & 5 & 10 & 11.6 & 0.2 & 3 & 4.6 \\
\hline 8 & 28 & M & 52 & $\mathrm{~T}$ & 8,9 & 25 & 15 & 20 & 27.5 & 0.72 & -5 & 2.5 \\
\hline 9 & 29 & M & 26 & $\mathrm{~T}$ & 4,5 & 22 & 20 & 23 & 25.3 & 0.65 & 1 & 3.3 \\
\hline 10 & 73 & $\mathrm{~F}$ & 26 & $\mathrm{~T}$ & 6,7 & 15 & 10 & 13 & 23.2 & 0.58 & -2 & 8.2 \\
\hline 11 & 73 & $\mathrm{~F}$ & 43 & $\mathrm{~T}$ & $7,8,9$ & 20 & 20 & 30 & 38.7 & 1.09 & 10 & 18.7 \\
\hline 12 & 16 & $\mathrm{~F}$ & 36 & $\mathrm{~T}$ & 8,9 & 10 & 6 & 10 & 13.4 & 0.26 & 0 & 3.4 \\
\hline 13 & 52 & $\mathrm{~F}$ & 25 & $\mathrm{TL}$ & 12,1 & 18 & 12 & 14 & 14.0 & 0.28 & -4 & -4.0 \\
\hline 14 & 69 & $\mathrm{~F}$ & 27 & $\mathrm{TL}$ & 11,12 & 34 & 24 & 26 & 34.8 & 0.96 & -8 & 0.8 \\
\hline 15 & 37 & M & 65 & $\mathrm{TL}$ & 1,2 & 10 & 6 & 10 & 15.9 & 0.34 & 0 & 5.9 \\
\hline 16 & 25 & $\mathrm{~F}$ & 112 & $\mathrm{TL}$ & 12,1 & 30 & 15 & 22 & 21.7 & 0.53 & -8 & -8.3 \\
\hline 17 & 29 & $\mathrm{~F}$ & 48 & $\mathrm{TL}$ & 1,2 & 20 & 5 & 10 & 26.5 & 0.69 & -10 & 6.5 \\
\hline 18 & 32 & M & 25 & $\mathrm{TL}$ & $11,12,1$ & 15 & 10 & 13 & 16.5 & 0.36 & -2 & 1.5 \\
\hline 19 & 61 & M & 36 & $\mathrm{TL}$ & 1,2 & 5 & 2 & 8 & 19.8 & 0.47 & 3 & 14.8 \\
\hline 20 & 38 & M & 66 & $\mathrm{TL}$ & 1,2 & 8 & 1 & 9 & 10.1 & 0.15 & 1 & 2.1 \\
\hline 21 & 30 & M & 33 & $\mathrm{TL}$ & 1,2 & 22 & 18 & 26 & 19.8 & 0.47 & 4 & -2.2 \\
\hline 22 & 41 & M & 62 & $\mathrm{TL}$ & $11,12,1,2$ & 30 & 24 & 28 & 31.7 & 0.86 & -2 & 1.7 \\
\hline 23 & 38 & $\mathrm{~F}$ & 81 & $\mathrm{TL}$ & 1,2 & 17 & 7 & 15 & 13.1 & 0.25 & -2 & -3.9 \\
\hline 24 & 24 & $\mathrm{~F}$ & 87 & $\mathrm{TL}$ & 12,1 & 15 & 7 & 11 & 11.6 & 0.2 & -4 & -3.4 \\
\hline 25 & 64 & $\mathrm{~F}$ & 49 & $\mathrm{TL}$ & 11,12 & 34 & 26 & 25 & 35.1 & 0.97 & -9 & 1.1 \\
\hline 26 & 44 & $\mathrm{~F}$ & 68 & $\mathrm{TL}$ & $10,11,12,1$ & 15 & 10 & 7 & 16.8 & 0.37 & -8 & 1.8 \\
\hline
\end{tabular}

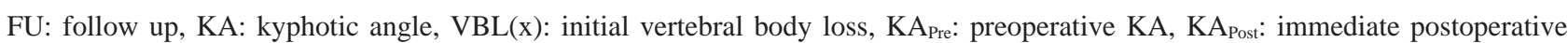
$\mathrm{KA}, \mathrm{KA}_{\text {Final }}$ : final postoperative $\mathrm{KA}, \mathrm{KA}$ Pd : predicted $\mathrm{KA}$ by formula ' $\mathrm{KA}_{\mathrm{Pd}}=5.5+30.5 \mathrm{VBL}(\mathrm{x})$ ' after conservative treatment with anti-tuberculous chemotherapy, $\Delta \mathrm{KA}_{\mathrm{R}}$ : radiographically measured kyphotic angle progression, $\Delta \mathrm{KA}$ : predicted kyphotic angle progression by formula-calculation.

into 10 equal parts on a lateral radiograph; measure the loss of height in tenths from each vertebra; and add the loss of height proportions from each vertebra. The sum of the destroyed portions ( $\Sigma$ VBL $i$ ) from the affected vertebrae was the $\mathrm{VBL}_{1}$ (Fig. 1).

Jain et al. ${ }^{7}$ proposed a different method for assessing the loss of the vertebral body, which we regarded as $\mathrm{VBL}_{2}$. Presumed normal anterior height $(\mathrm{H})$ of the affected vertebral body was arithmetic mean of the anterior heights of the upper and lower normal vertebral bodies. The loss of the anterior height was calculated by subtracting the measured height from the $\mathrm{H}$. The anterior height loss per affected vertebral body, was then summed to obtain the total height loss ( $\Sigma \mathrm{VBL} i$ ). The $\mathrm{VBL}_{2}$ was the ratio of $\Sigma \mathrm{VBL} i$ to $\mathrm{H}$. In this study, the arithmetic mean of the above mentioned two calculations was used as the initial vertebral body loss:
$\operatorname{VBL}(\mathrm{x})=\left(\mathrm{VBL}_{1}+\mathrm{VBL}_{2}\right) / 2($ Fig. 1).

\section{Patient assessment by subgroup}

The patients were divided into three independent subgroups. The first subgroup was based on the region affected: thoracic $(\mathrm{T})(\mathrm{n}=12)$, thoracolumbar $(\mathrm{TL})(\mathrm{n}=14)$ and combined $(\mathrm{T}+\mathrm{TL})(\mathrm{n}=26)$. The second subgroup was based on the $\mathrm{KA}_{\text {Pre }}: \mathrm{KA}_{\text {Pre }} \leq 30^{\circ} \quad(\mathrm{n}=22), \mathrm{KA}_{\text {Pre }} \leq 25^{\circ} \quad(\mathrm{n}=19)$, $\mathrm{KA}_{\text {Pre }} \leq 20^{\circ}(\mathrm{n}=15)$, and $\mathrm{KA}_{\text {Pre }} \leq 15^{\circ} \quad(\mathrm{n}=10)$. The third subgroup was based on the $\operatorname{VBL}(\mathrm{x}): \operatorname{VBL}(\mathrm{x}) \leq 1.0(\mathrm{n}=23)$, $\operatorname{VBL}(x) \leq 0.75(n=20)$, and $\operatorname{VBL}(x) \leq 0.5(n=12)$. The ' $\mathrm{T}+\mathrm{TL}$ ' group refers to all patients. The range was set by the authors to include a gradual increase in the range in an attempt to identify the threshold values to use as guidelines, assuming that that the increase in $\mathrm{KA}$ and $\operatorname{VBL}(\mathrm{x})$ were 
associated with the progression of the disease.

For each subgroup, the $\Delta \mathrm{KA}_{\mathrm{R}}$ and $\Delta \mathrm{KA}_{\mathrm{P}}$ were compared using a paired t-test. A p-value $<0.05$ was considered significant (SPSS ver. 10.0; SPSS Inc., Chicago, IL, USA).

\section{Results}

A mean of 2.4(2-4) vertebral bodies were affected by bone destruction. Preoperative Pott's paraplegia and para-
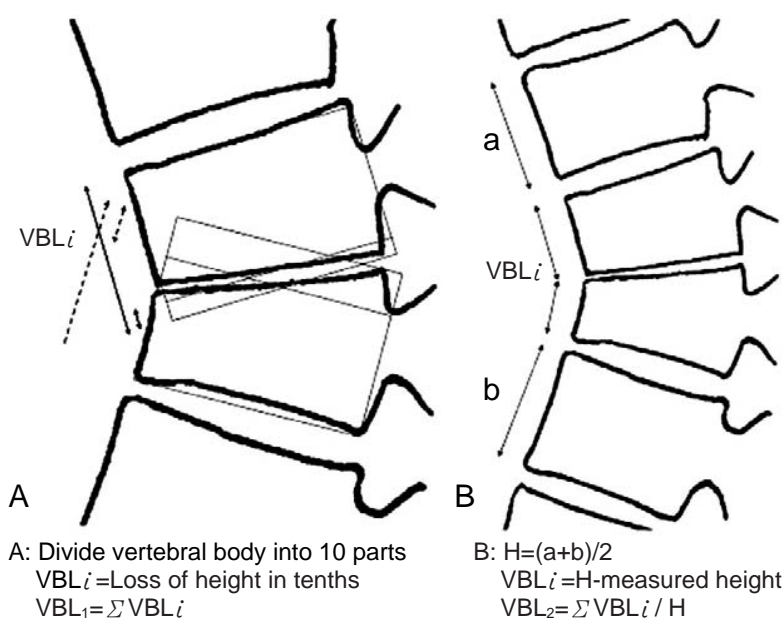

Fig. 1. The diagram shows the method used to assess the preoperative initial vertebral body loss $(\operatorname{VBL}(\mathrm{x}))$. (A) $\mathrm{VBL}_{1}$ was defined as the fractional loss of the vertebral body area. When more than one vertebra was involved, the sum of each loss ( $\Sigma$ VBLi) was calculated as the $\mathrm{VBL}_{1}$. (B) $\mathrm{VBL}_{2}$ was defined as the fractional loss of the anterior vertebral body height, assuming that the original anterior vertebral height $(\mathrm{H})$ was the arithmetic mean of the anterior height of the upper (a) and lower (b) normal vertebral bodies. In this study the arithmetic mean of $\mathrm{VBL}_{1}$ and $\mathrm{VBL}_{2}$ was used as the 'VBL(x)'. paresis were observed in 8 of the 26 patients. Table 1 lists the patient demographic information.

\section{Regional subgroups}

In the $\mathrm{T}$ group, the $\mathrm{KA}_{\text {Pre }}, \mathrm{KA}_{\text {Final }}$ and $\mathrm{KA}_{\mathrm{Pd}}$ was $21.8^{\circ} \pm$ $9.4^{\circ}, 21.9^{\circ} \pm 8.8^{\circ}$ and $25.9^{\circ} \pm 8.8^{\circ}$, respectively. The radiographically measured kyphotic angle progression $\left(\triangle \mathrm{KA}_{\mathrm{R}}\right)$ and predicted kyphotic angle progression $\left(\triangle \mathrm{KA}_{\mathrm{P}}\right)$ were significantly different ( $\mathrm{p}=0.027$ ) (Fig. 2, Table 2).

In the TL group, the $\mathrm{KA}_{\text {Pre }}, \mathrm{KA}_{\text {Final }}$ and $\mathrm{KA}_{\mathrm{Pd}}$ was $19.5^{\circ} \pm$ $9.4^{\circ}, 16.0^{\circ} \pm 7.7^{\circ}$ and $20.5^{\circ} \pm 8.4^{\circ}$, respectively. A comparison of the kyphotic angle progression between $\Delta \mathrm{KA}_{\mathrm{R}}$ and $\triangle \mathrm{KA}_{\mathrm{P}}$ showed a significant difference ( $\left.\mathrm{p}=0.017\right)$ (Fig. 2, Table 2).

For the T-TL group, which represents the entire cohort, the $\mathrm{KA}_{\text {Pre }}, \mathrm{KA}_{\text {Final }}$ and $\mathrm{KA}_{\mathrm{Pd}}$ was $20.6^{\circ} \pm 9.3^{\circ}, 18.7^{\circ} \pm 8.6^{\circ}$ and $23.0^{\circ} \pm 8.8^{\circ}$, respectively. The $\Delta \mathrm{KA}_{\mathrm{R}}$ was significantly smaller than the $\Delta \mathrm{KA}_{\mathrm{P}}(\mathrm{p}=0.001)$ (Fig.2, Table 2).

\section{KA subgroup}

For the $\mathrm{KA}_{\text {Pre }} \leq 30^{\circ}$ group, the $\mathrm{KA}_{\text {Pre }} \mathrm{KA}_{\text {Final }}$ and $\mathrm{KA}_{\text {Pd }}$ was $17.9^{\circ} \pm 7.4^{\circ}, 17.1^{\circ} \pm 8.1^{\circ}$, and $20.6^{\circ} \pm 7.3^{\circ}$, respectively (Table 2). The $\Delta \mathrm{KA}_{\mathrm{R}}$ was significantly smaller than the $\Delta$ $\mathrm{KA}_{\mathrm{p}}(\mathrm{p}=0.001)$. Each subgroup of KA was analyzed to determine if the $\triangle \mathrm{KA}_{\mathrm{R}}$ was significantly smaller than the predicted outcome, a kyphogenesis of $\triangle \mathrm{KA}_{\mathrm{Pd}}$ (Fig.3, Table 2).

\section{VBL(x) subgroup}

In the $\operatorname{VBL}(\mathrm{x}) \leq 1.0$ group, the $\mathrm{KA}_{\text {Pre }} \mathrm{KA}_{\text {Final }}$ and $\mathrm{KA}_{\mathrm{Pd}}$ was $19.2^{\circ} \pm 8.6^{\circ}, 17.3^{\circ} \pm 7.8^{\circ}$, and $21.1^{\circ} \pm 7.4^{\circ}$, respectively. The

Table 2. The mean $( \pm$ SD) of the results

\begin{tabular}{|c|c|c|c|c|c|c|c|c|}
\hline Level & subgroup & $\mathrm{N}$ & $\mathrm{KA}_{\text {Pre }}\left({ }^{\circ}\right)$ & $\mathrm{KA}_{\text {Post }}\left({ }^{\circ}\right)$ & $\mathrm{KA}_{\text {Final }}\left({ }^{\circ}\right)$ & $\mathrm{KA}_{\mathrm{Pd}}\left({ }^{\circ}\right)$ & $\operatorname{VBL}(\mathrm{x})$ & $\begin{array}{c}\mathrm{p} \text {-value } \\
\left(\Delta \mathrm{KA}_{\mathrm{R}} \mathrm{V}_{\mathrm{s}} \Delta \mathrm{KA}_{\mathrm{Pd}}\right)\end{array}$ \\
\hline $\mathrm{T}$ & Regional & 12 & $21.8 \pm 9.4$ & $15.7 \pm 7.0$ & $21.9 \pm 8.8$ & $25.9 \pm 8.8$ & $0.67 \pm 0.29$ & 0.027 \\
\hline TL & Regional & 14 & $19.5 \pm 9.4$ & $11.9 \pm 8.3$ & $16.0 \pm 7.7$ & $20.5 \pm 8.4$ & $0.49 \pm 0.28$ & 0.017 \\
\hline $\mathrm{T}+\mathrm{TL}$ (whole) & Regional & 26 & $20.6 \pm 9.3$ & $13.7 \pm 7.8$ & $18.7 \pm 8.6$ & $23.0 \pm 8.8$ & $0.57 \pm 0.29$ & 0.001 \\
\hline $\mathrm{T}+\mathrm{TL}$ & $\mathrm{KA} 1 \leq 30^{\circ}$ & 22 & $17.9 \pm 7.4$ & $11.6 \pm 6.4$ & $17.1 \pm 8.1$ & $20.6 \pm 7.3$ & $0.50 \pm 0.24$ & 0.009 \\
\hline $\mathrm{T}+\mathrm{TL}$ & $\mathrm{KA} 1 \leq 25^{\circ}$ & 19 & $16.0 \pm 5.9$ & $10.3 \pm 5.8$ & $15.8 \pm 8.0$ & $19.6 \pm 7.3$ & $0.46 \pm 0.24$ & 0.015 \\
\hline $\mathrm{T}+\mathrm{TL}$ & $\mathrm{KA} 1 \leq 20^{\circ}$ & 15 & $14.0 \pm 4.9$ & $8.5 \pm 4.9$ & $13.1 \pm 6.0$ & $18.3 \pm 7.5$ & $0.42 \pm 0.24$ & 0.002 \\
\hline $\mathrm{T}+\mathrm{TL}$ & $\mathrm{KA} 1 \leq 15^{\circ}$ & 10 & $11.5 \pm .4 .0$ & $6.8 \pm 3.5$ & $10.6 \pm 2.5$ & $15.8 \pm 4.2$ & $0.34 \pm 0.14$ & 0.003 \\
\hline $\mathrm{T}+\mathrm{TL}$ & $\mathrm{VBL} \leq 1.0$ & 23 & $19.2 \pm 8.6$ & $12.4 \pm 7.2$ & $17.3 \pm 7.8$ & $21.1 \pm 7.4$ & $0.50 \pm 0.24$ & 0.005 \\
\hline $\mathrm{T}+\mathrm{TL}$ & $\mathrm{VBL} \leq 0.75$ & 20 & $17.2 \pm 7.2$ & $10.6 \pm 5.7$ & $15.9 \pm 7.5$ & $19.1 \pm 5.8$ & $0.45 \pm 0.19$ & 0.024 \\
\hline $\mathrm{T}+\mathrm{TL}$ & $\mathrm{VBL} \leq 0.5$ & 12 & $13.1 \pm 5.1$ & $7.9 \pm 4.6$ & $12.3 \pm 5.1$ & $15.2 \pm 3.4$ & $0.32 \pm 0.11$ & 0.071 \\
\hline
\end{tabular}

$\mathrm{KA}_{\text {Pre }}$ : preoperative KA, KA $\mathrm{K}_{\text {Post }}$ : immediate postoperative $\mathrm{KA}, \mathrm{KA}_{\text {Final }}$ : final postoperative KA, KA Pd predicted KA by formula, $\operatorname{VBL}(\mathrm{x})$ : initial vertebral body loss, $\triangle \mathrm{KA}_{\mathrm{R}}$ : radiographically measured kyphotic angle progression, $\mathrm{T}$ : thoracic, TL: Thoracolumbar. 
$\triangle \mathrm{KA}_{\mathrm{R}}$ was significantly smaller than the $\Delta \mathrm{KA}_{\mathrm{P}}(\mathrm{p}=0.005)$. In the $\operatorname{VBL}(\mathrm{x}) \leq 0.75$ group, the $\triangle \mathrm{KA}_{\mathrm{R}}$ was significantly smaller than the $\triangle \mathrm{KA}_{\mathrm{P}}(\mathrm{p}=0.024)$ (Fig. 4, Table 2).

However, in the $\operatorname{VBL}(\mathrm{x}) \leq 0.5$ group, the $\mathrm{KA}_{\text {Pre }} \mathrm{KA}_{\text {Final }}$ and $\mathrm{KA}_{P d}$ was $13.1^{\circ} \pm 5.1^{\circ}, 12.3^{\circ} \pm 5.1^{\circ}$ and $15.2^{\circ} \pm 3.4^{\circ}$, respectively (Table 2). The $\Delta \mathrm{KA}_{\mathrm{R}}$ and $\Delta \mathrm{KA}_{\mathrm{p}}$ were similar $(\mathrm{p}=0.071)$ (Fig. 4, Table 2).

\section{Discussion}

The fifth MRC report of a 5-year follow-up ${ }^{2}$ showed that ambulatory antituberculous chemotherapy was successful when compared with combined bed rest for six months, or a plaster-of-Paris jacket for nine months. Antituberculous medication was used for 18 months, and the regimen included isoniazid and para-aminosalicylic acid with or without additional streptomycin during the first three months ${ }^{2}$. Tull and Kumar ${ }^{8}$, Tuli ${ }^{9}$ reported that only $19 \%$ of patients showed progression of their kyphotic deformity $>10^{\circ}$ after rest and conservative treatment with antituberculous drugs.

The sixth MRC report of a 5-year follow-up ${ }^{10}$ showed similarly favorable results with ambulatory chemotherapy versus debridement, as well as with debridement versus radical treatment with autologous bone graft reconstruction. The favorable results included the following: return to physical activity, absence of neurological abnormalities, absence of abscess formation, absence of the development of sinus tracts, and the presence of radiographically quiescent spinal lesions ${ }^{10}$.

The eighth MRC report after a 10-year follow-up ${ }^{6}$ compared a radical anterior autologous bone reconstruction with debridement of the abnormal tissue leaving the apparently unaffected bone. The sagittal profile was superior after the radical series compared to after the debridement cases. Vertebral body loss increased by 0.05 for the radical cases, while it increased by 0.23 for the debridement cases. The KA decreased by $1.4^{\circ}$ for the radical cases, whereas for the debridement cases, it increased by $9.8^{\circ}$ in the thoracic and thoracolumbar lesions. The KA decreased by $0.5^{\circ}$ in the radical cases, whereas it increased by $7.6^{\circ}$ for the debridement cases with lumbar lesions.

The bone loss and increase in KA usually occurred within the first 18 months from the initial diagnosis and treatment. Upadhyay et al. ${ }^{11}$ reported that anterior column support resulted in less kyphotic deformity than simple anterior debridement. Rajasekaran and Shanmugasundarm ${ }^{12}$ reported less kyphogenesis with little bone loss in the single-segment lesions than in multi-segment lesions.

Firm fixation is essential for the healing of bone infections and bone fusion, and cast immobilization has been used to treat vertebral infections. The development of instruments has led to successful treatment by instrumented fusion for vertebral infections. Moon et al. ${ }^{13}$ reported that the kyphosis could be corrected and maintained effectively in adult spinal TB by adding posterior instrumented fusion. Sundararaj et al. ${ }^{14}$ reported the following advantages of adjuvant posterior instrumented fusion: prevention of graft dislodgement; correcting and maintaining the kyphosis; resulting in a superior outcome for intervertebral bone fusion. No additional risk was found for persistent infections due to the posterior instrumentation ${ }^{14,15}$. For pyogenic infections, internally fixed metal appliances facilitate the attachment and proliferation of microbes, forms a biofilm

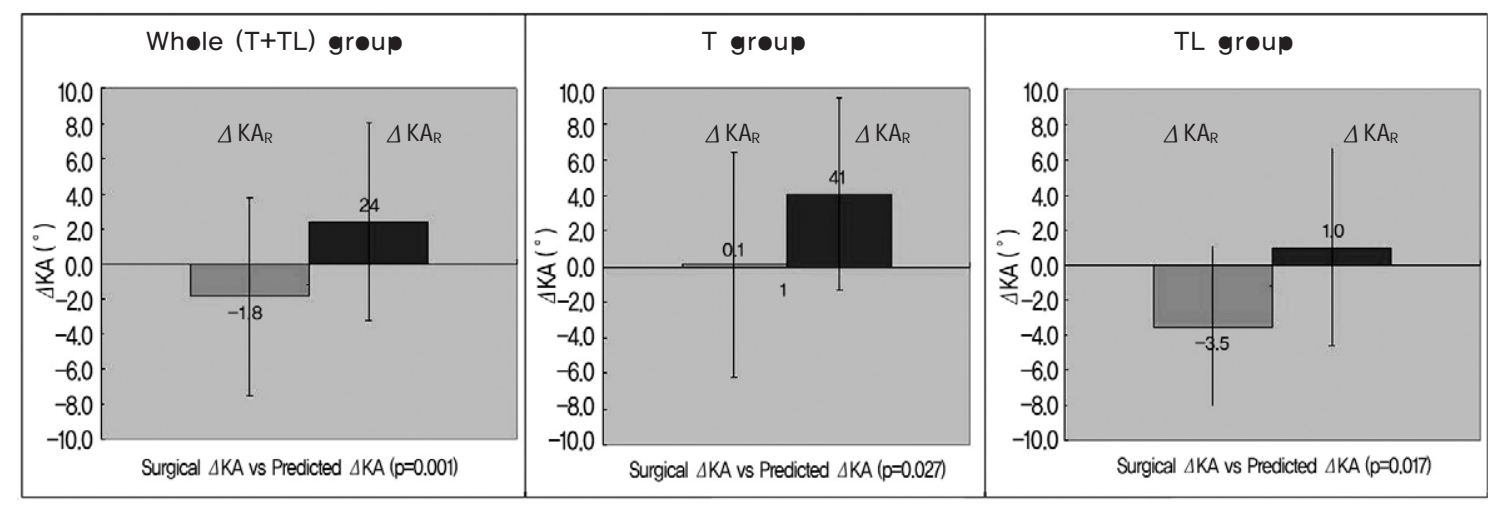

Fig. 2. Comparison of the kyphotic angle (KA) progression ( $\Delta \mathrm{KA})$ in the subgroups: thoracic (T), thoracolumbar (TL), and combined (T+TL) groups. The surgical $\Delta \mathrm{KA}\left(\Delta \mathrm{KA}_{\mathrm{R}}\right)$ was significantly smaller than the predicted $\Delta \mathrm{KA}$ $\left(\Delta \mathrm{KA}_{\mathrm{P}}\right)$ which is the predicted outcome of conservative treatment: $\mathrm{p}=0.027(\mathrm{~T}) ; \mathrm{p}=0.017(\mathrm{TL})$; and $\mathrm{p}=0.001$ $(\mathrm{T}+\mathrm{TL})$. 
on the surface of the metal and prevents antibiotics from reaching the infection and/or inflammation and thereby healing. This occasionally necessitates removal of the metal implants ${ }^{16}$. Ha et al. ${ }^{17}$ performed an in-vitro experiment and reported much greater adherence and multiplication of biofilm formation on the metal segments with Staphylococ- cus epidermidis strains than in Mycobacterium tuberculosis strains. They demonstrated a more favorable environment for instrumentation in the treatment of Tbc spondylitis. Instrumentation to the posterior side, which is opposite to the initial infection, is not considered to be harmful ${ }^{17}$.

For measuring the $\operatorname{VBL}(\mathrm{x})$, Rajasekaran and Shanmuga-

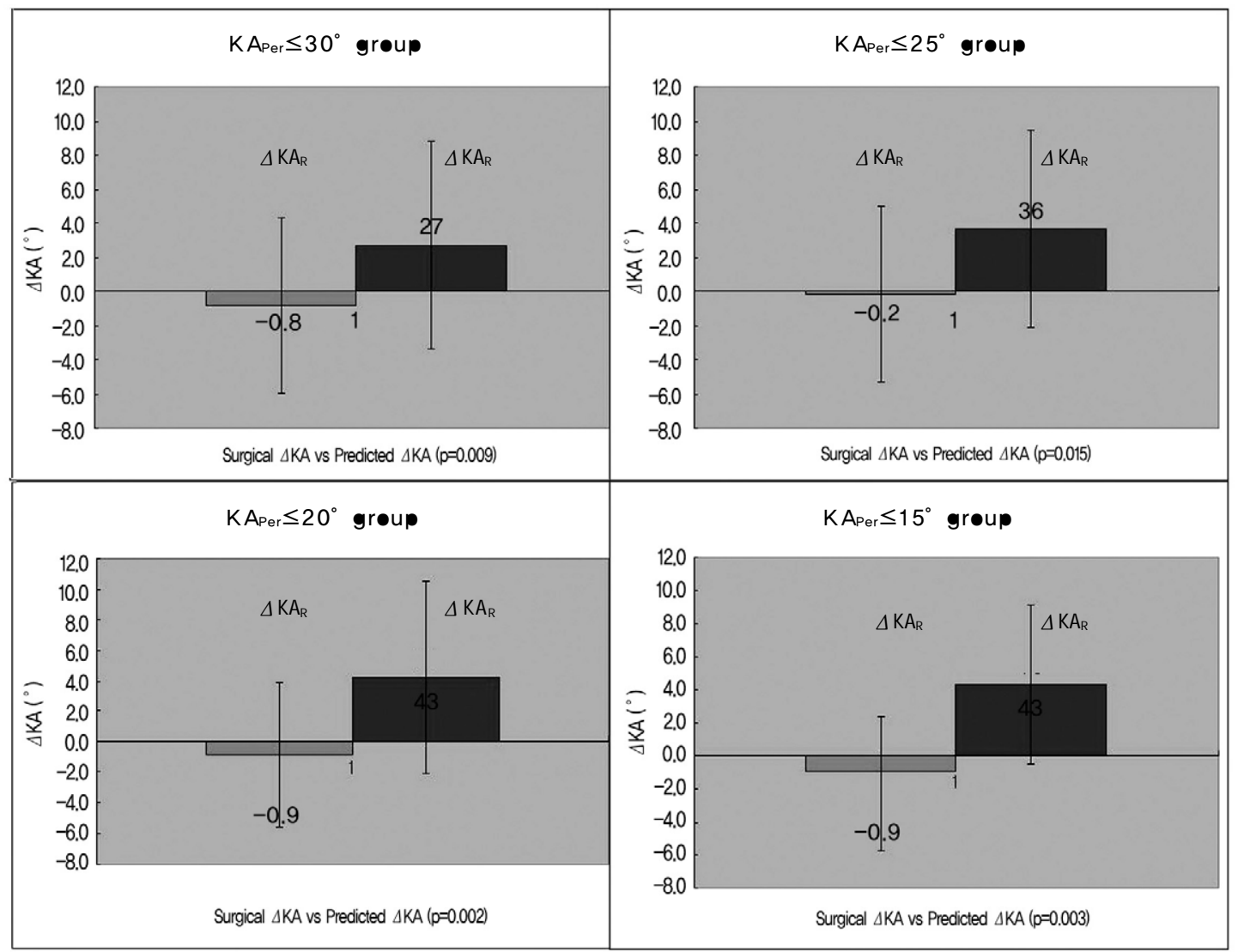

Fig. 3. Comparison of the $\Delta \mathrm{KA}$ by the preoperative $\mathrm{KA}\left(\mathrm{KA} \mathrm{Pre}_{\mathrm{P}}\right)$ subgroups. For the subgroups of ' $\mathrm{KA}$ Pre $\leq 30^{\circ}$, , ' $\mathrm{KA}_{\text {Pre }} \leq 25^{\circ}$ ', ' $\mathrm{KA} \mathrm{Are}_{\text {Pre }} \leq 20^{\circ}$ ', and ' $\mathrm{KA} \mathrm{Are}_{\text {Pre }} \leq 15^{\circ}$ ', the surgical $\Delta \mathrm{KA}\left(\Delta \mathrm{KA}_{\mathrm{R}}\right)$ was significantly smaller than the predicted $\Delta \mathrm{KA}\left(\Delta \mathrm{KA}_{\mathrm{P}}\right): \mathrm{p}=0.009\left(\mathrm{KA}_{\mathrm{Pre}} \leq 30^{\circ}\right) ; \mathrm{p}=0.015\left(\mathrm{KA}_{\mathrm{Pre}} \leq 25^{\circ}\right) ; \mathrm{p}=0.002\left(\mathrm{KA}_{\operatorname{Pre}} \leq 20^{\circ}\right)$; and $\mathrm{p}=0.003\left(\mathrm{KA} A_{\operatorname{Pr}}\right.$ $\leq 15^{\circ}$ ), respectively.
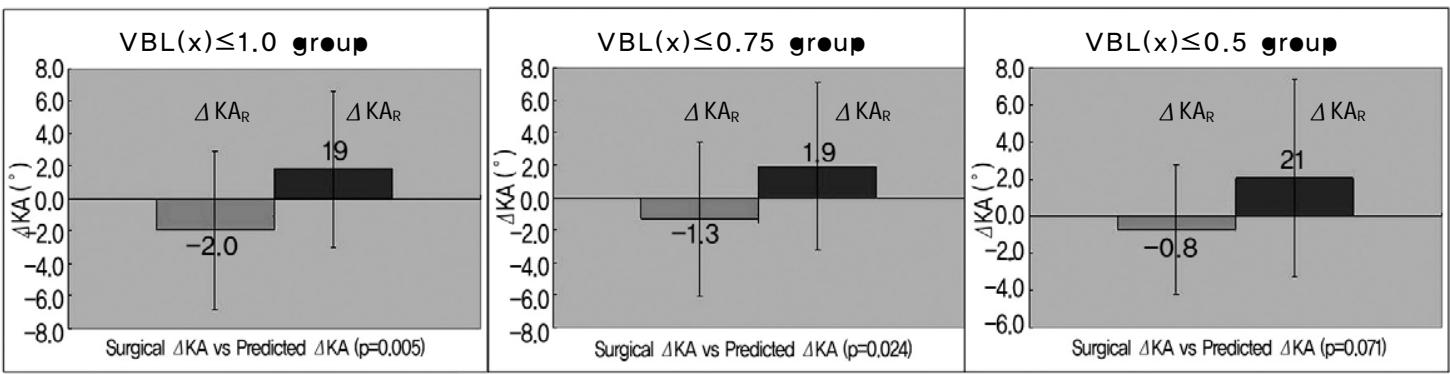

Fig. 4. Comparison of $\Delta \mathrm{KA}$ in the $\operatorname{VBL}(\mathrm{x})$ subgroups ('VBL(x) $\leq 1.0$ ', ' $\operatorname{VBL}(\mathrm{x}) \leq 0.75$ ', and ' $\operatorname{VBL}(\mathrm{x}) \leq 0.5$ '). In the ' $\operatorname{VBL}(\mathrm{x}) \leq 0.5$ ' group, the $\Delta \mathrm{KA}_{\mathrm{R}}$ was not significantly different from the $\Delta \mathrm{KA}_{\mathrm{P}}$ which is the predicted $\mathrm{KA}$ after conservative treatment $(\mathrm{p}=0.071)$. In the other groups, $\Delta \mathrm{KA}_{\mathrm{R}}$ was significantly smaller than $\Delta \mathrm{KA}_{\mathrm{P}}$, indicating smaller amount of kyphogenesis in the surgical group: $\mathrm{p}=0.005(\operatorname{VBL}(\mathrm{x}) \leq 1.0)$; and $\mathrm{p}=0.024(\operatorname{VBL}(\mathrm{x}) \leq 0.75)$. 
sundaram ${ }^{3}$ divided each affected vertebral body into 10 parts (Fig. 1). This calculation led to frequent ambiguity and arbitrary measurements because severely damaged vertebrae often do not have definite borders? ${ }^{7}$. On the other hand, Jain et al. ${ }^{7}$ used the arithmetic mean from the anterior heights of the upper and lower vertebrae, which were normal, as the 'presumed normal anterior height' at the affected level. The 'anterior height loss' is the difference between the presumed normal height and actual height measured. In lesions at multiple levels, the anterior height losses were added to obtain the 'total height loss'. The 'initial vertebral body loss' is the ratio between the 'total height loss' to the 'presumed normal anterior height'. Jain et al. ${ }^{7}$ suggested an approximate $76 \%$ accuracy using their method for conservative treatment. However, this method may not reflect the precise vertebral body loss if the anterior cortical bone is spared selectively in the lesion distribution. In this study, the arithmetic mean of the above two calculations for the VBL ( $\mathrm{x}$ was used) to ameliorate the shortcomings of each (Fig. 1).

The results showed significantly less thoracic KA progression after surgery than the predicted outcome after conservative treatment: $\left(\Delta \mathrm{KA}_{R}=0.1^{\circ} \pm 6.3^{\circ}\right.$ vs. $\Delta \mathrm{KA}_{\mathrm{P}}=4.1^{\circ} \pm$ $5.4 \mathrm{v} ; \mathrm{p}=0.006$ ). In addition, the thoracolumbar KA progression was significantly less after surgery than after the predicted-conservative treatment: $\left(\Delta \mathrm{KA}_{R}=-3.5^{\circ} \pm 4.6^{\circ}\right.$ vs. $\Delta$ $\left.\mathrm{KA}_{\mathrm{P}}=1.0^{\circ} \pm 5.6^{\circ} ; \mathrm{p}=0.000\right)$. The KA progression of the entire cohort including the thoracic and thoracolumbar spine subgroups was significantly less after surgery than after the predicted outcome with conservative treatment:
( $\Delta \mathrm{KA}_{\mathrm{R}}=-1.8^{\circ} \pm 5.6^{\circ}$ vs. $\left.\Delta \mathrm{KA}_{\mathrm{P}}=2.4^{\circ} \pm 5.6^{\circ} ; \mathrm{p}=0.001\right)$. The results suggest that surgical treatment was justified based on the sagittal profile outcome because the $\Delta \mathrm{KA}_{\mathrm{R}}$, which represents the kyphotic angle progression after surgery, was significantly smaller than the $\Delta \mathrm{KA}$, which represents the kyphotic angle progression in the formula for predicting the outcome.

For the KA subgroup, all subgroups with a ' $\mathrm{KA} \leq 30^{\circ}$,, ' $\mathrm{KA} \leq 20^{\circ}$ ' and ' $\mathrm{KA} \leq 15^{\circ}$ ' showed a significantly smaller $\Delta \mathrm{KA}_{\mathrm{R}}$ than $\Delta \mathrm{KA}_{\mathrm{P}}$, suggesting less kyphotic angle progression after surgical treatment than after the predicted outcome of conservative treatment-alone. The same conclusion in all KA subgroups confirms the efficacy of surgical treatment. However, the KA subgroup results did not suggest a range in which conservative treatment-alone might be justified.

For the $\operatorname{VBL}(\mathrm{x})$ subgroup, the $\Delta \mathrm{KA}_{\mathrm{R}}$ and the $\Delta \mathrm{KA}_{\mathrm{P}}$ were not significantly different in the ' $\operatorname{VBL}(\mathrm{x}) \leq 0.5$ ' subgroup $(\mathrm{p}=0.071)$. This suggests that the surgical treatment group did not have a significantly superior sagittal profile compared to the predicted outcome of conservative treatment. As the progression of kyphosis was the main concern for the surgical treatment of Tbc spondylitis, conservative treatment might be indicated initially in patients identified with a $\operatorname{VBL}(\mathrm{x}) \leq 0.5$. The other $\operatorname{VBL}(\mathrm{x})$ subgroups showed that the $\Delta \mathrm{KA}_{\mathrm{R}}$ was significantly smaller than the $\Delta \mathrm{KA}_{\mathrm{P}}$, justifying surgical treatment for improved outcome on the sagittal profile. The surgical treatment used in all cases was an anterior-posterior combined surgery (anterior decompression, interbody fusion, and posterior instrumented

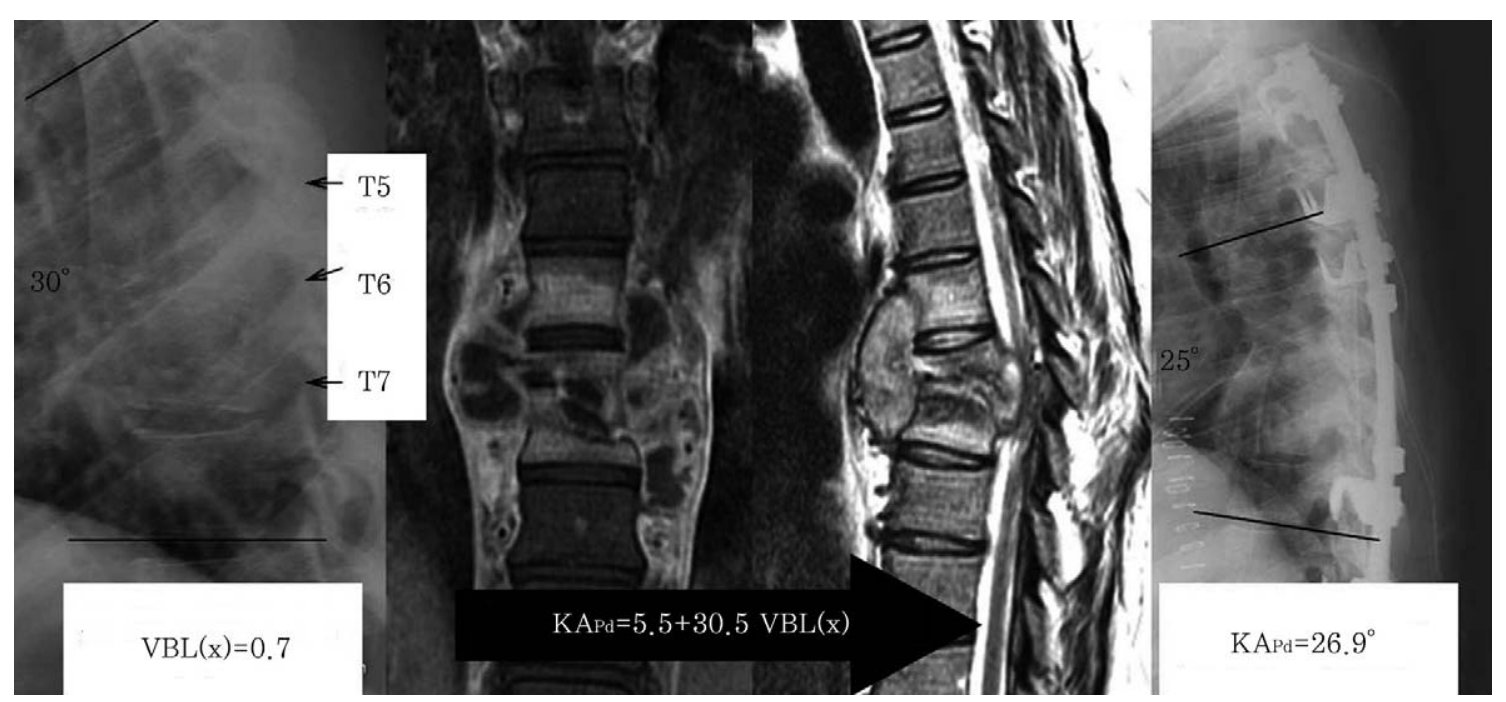

Fig. 5. A 26-year-old female patient with $\mathrm{T}$ 5-7 Tbc spondylitis, with a $\operatorname{VBL}(\mathrm{x})$ of 0.7 : the $\mathrm{KA}$ Pre was $30^{\circ}$ before surgery and final postoperative $\mathrm{KA}\left(\mathrm{KA}_{\text {Final }}\right)$ was $25^{\circ}$. The predicted $\mathrm{KA}\left(\mathrm{KA}_{\mathrm{Pd}}\right)$ was $26.9^{\circ}$. 
fusion with bone graft) (Fig. 5). The KA was corrected substantially by the combined anterior column support and posterior instrumentation and the correction was maintained.

The limitations of this study include the following. The control group consisted of theoretical, calculated, results. The accuracy of the 'equation' requires further statistical validation to be considered a reliable control group. However, in a limited cohort with a small number of patients, different patients with the same KA and $\operatorname{VBL}(\mathrm{x})$ might include a range of factors, such as co-morbidities that reduce the homogeneity of the group, which bias the comparison. This study compared the surgical and predicted results on the same patient. The $\operatorname{VBL}(\mathrm{x})$ was calculated by taking the mean of the two methods but this value requires further validation. In addition to the sagittal profile discussed in this study, the presence of neurological complications would be an additional independent factor indicating a need for surgical treatment. Subsidence at the anterior strut graft would be likely to occur due to endplate injury either by the disease process or by the surgical procedure, even though the disc space is destroyed less aggressively compared to the pathogenesis of pyogenic spondylitis ${ }^{18}$. This endplate -associated subsidence might explain some of the variance of the subsidence observed in our data. However, the statistical analysis still leads to certain conclusions based on a comparison of the two groups. In subgroup analysis, conservative treatment appears to be warranted with an initial $\operatorname{VBL}(\mathrm{x})$ of $\leq$ 0.5 . Nevertheless, the KA subgrouping did not suggest guidelines for conservative treatment. Further study with a larger cohort would enable statistical analysis to improve the categorization of patients, as well as a comparison of surgically and medically treated groups.

\section{Conclusions}

For patients with thoracic and thoracolumbar Tbc spondylitis, surgical treatment was more effective for kyphosis correction than the predicted outcome of conservative treatment. An initial VBL(x) of $\leq 0.5$ on the sagittal profile after surgical treatment was not significantly superior to the outcome predicted by conservative treatment. The $\mathrm{KA}$ is not a parameter that can be used to determine whether to perform surgical treatment. These results suggest that a $\operatorname{VBL}(\mathrm{x})$ of $\leq 0.5$ is an indication for conservative antituberculous chemotherapy.

\section{REFERENCE}

1. Tuli SM: Severe kyphotic deformity in tuberculosis of the spine. Int Orthop 1995; 19: 327-331.

2. A five-year assessment of controlled trials of in-patient and out-patient treatment and of plaster-of-Paris jackets for tuberculosis of the spine in children on standard chemotherapy. Studies in Masan and Pusan, Korea. Fifth report of the Medical Research Council Working Party on tuberculosis of the spine. J Bone Joint Surg Br 1976; 58: 399-411.

3. Rajasekaran S, Shanmugasundaram TK: Prediction of the angle of gibbus deformity in tuberculosis of the spine. $\mathrm{J}$ Bone Joint Surg Am 1987; 69: 503-509.

4. Moon MS, Moon YW, Moon JL, Kim SS, Sun DH: Conservative treatment of tuberculosis of the lumbar and lumbosacral spine. Clin Orthop Relat Res 2002; (398): 40-49.

5. Konstam PG, Blesovsky A: The ambulant treatment of spinal tuberculosis. Br J Surg 1962; 50: 26-38.

6. A 10-year assessment of a controlled trial comparing debridement and anterior spinal fusion in the management of tuberculosis of the spine in patients on standard chemotherapy in Hong Kong. Eighth Report of the Medical Research Council Working Party on Tuberculosis of the Spine. J Bone Joint Surg Br 1982; 64: 393-398.

7. Jain AK, Aggarwal PK, Arora A, Singh S: Behaviour of the kyphotic angle in spinal tuberculosis. Int Orthop 2004; 28: $110-114$

8. Tull SM, Kumar S: Early results of treatment of spinal tuberculosis by triple drug therapy. Clin Orthop Relat Res 1971; (81): 56-70.

9. Tuli SM: Results of treatment of spinal tuberculosis by "middle-path" regime. J Bone Joint Surg Br 1975; 57: 1323.

10. Five-year assessments of controlled trials of ambulatory treatment, debridement and anterior spinal fusion in the management of tuberculosis of the spine. Studies in Bulawayo (Rhodesia) and in Hong Kong. Sixth report of the Medical Research Council Working Party on Tuberculosis of the Spine. J Bone Joint Surg Br 1978; 60: 163-177.

11. Upadhyay SS, Sell P, Saji MJ, Sell B, Hsu LC: Surgical management of spinal tuberculosis in adults. Hong Kong operation compared with debridement surgery for short and long term outcome of deformity. Clin Orthop Relat Res 1994; (302): 173-182.

12. Rajasekaran S, Soundarapandian S: Progression of 
kyphosis in tuberculosis of the spine treated by anterior arthrodesis. J Bone Joint Surg Am 1989; 71: 1314-1323.

13. Moon MS, Woo YK, Lee KS, et al: Posterior instrumentation and anterior interbody fusion for tuberculous kyphosis of dorsal and lumbar spines. Spine (Phila Pa 1976) 1995; 20: 1910-1916.

14. Sundararaj GD, Behera S, Ravi V, et al: Role of posterior stabilisation in the management of tuberculosis of the dorsal and lumbar spine. J Bone Joint Surg Br 2003; 85: 100-106.

15. Oga M, Arizono T, Takasita M, Sugioka Y: Evaluation of the risk of instrumentation as a foreign body in spinal tuberculosis. Clinical and biologic study. Spine (Phila Pa 1976) 1993; 18: 1890-1894.
16. Gracia E, Fernandez A, Conchello P, et al: Adherence of Staphylococcus aureus slime-producing strain variants to biomaterials used in orthopaedic surgery. Int Orthop 1997; 21: 46-51.

17. Ha KY, Chung YG, Ryoo SJ: Adherence and biofilm formation of Staphylococcus epidermidis and Mycobacterium tuberculosis on various spinal implants. Spine (Phila $\mathrm{Pa}$ 1976) 2005; 30: 38-43.

18. Ha KY, Shin JH, Kim KW, Na KH: The fate of anterior autogenous bone graft after anterior radical surgery with or without posterior instrumentation in the treatment of pyogenic lumbar spondylodiscitis. Spine (Phila Pa 1976) 2007; 32: 1856-1864. 